\title{
PRUNE2 inhibits progression of colorectal cancer in vitro and in vivo
}

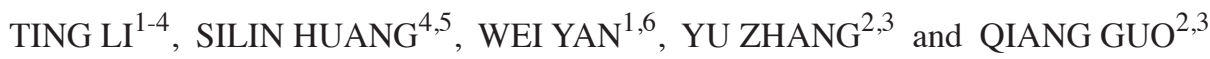 \\ ${ }^{1}$ Faculty of Environmental Science and Engineering, Kunming University of Science and Technology, Kunming, \\ Yunnan 650500; ${ }^{2}$ Department of Gastroenterology, The First People's Hospital of Yunnan Province, Kunming, Yunnan 650032; \\ ${ }^{3}$ Department of Gastroenterology, The Affiliated Hospital of Kunming University of Science and Technology; \\ ${ }^{4}$ Medical School, Kunming University of Science and Technology, Kunming, Yunnan 650500; \\ ${ }^{5}$ Department of Gastroenterology, South China Hospital, Health Science Center, Shenzhen University, \\ Shenzhen, Guangzhou 518116; ${ }^{6}$ Faculty of Life Science and Technology, \\ Kunming University of Science and Technology, Kunming, Yunnan 650500, P.R. China
}

Received October 6, 2021; Accepted December 9, 2021

DOI: $10.3892 /$ etm.2021.11092

\begin{abstract}
Prune homolog 2 with BCH domain (PRUNE2) is associated with prostate cancer, neuroblastoma, glioblastoma and melanoma; however, the function of PRUNE2 in colorectal cancer (CRC) remains unknown. The present study aimed to evaluate the effects of PRUNE2 on the development of CRC. The biological function of PRUNE2 in CRC cell lines was investigated by using Cell Counting Kit-8, colony formation, flow cytometry and Transwell assay. Additionally, a mouse model was established to investigate the effect of PRUNE2 on metastasis of CRC cells. The expression levels of PRUNE2 were lower in CRC compared with adjacent normal tissue and this expression pattern was associated with poor relapse-free survival probability. PRUNE2 overexpression significantly decreased cell proliferation and invasion, increased cell apoptosis and arrested the cell cycle. Consistently, it increased the protein expression levels of pro-apoptosis genes and decreased the expression of antiapoptotic proteins. PRUNE2 knockdown had the opposite effects. Furthermore, PRUNE2 overexpression decreased the tumorigenicity of CRC cells. In conclusion, PRUNE2 decreased cell survival, proliferation, invasion and tumorigenicity and promoted apoptosis, suggesting that PRUNE2 may function as a tumor-suppressive gene in CRC.
\end{abstract}

Correspondence to: Dr Qiang Guo or Dr Yu Zhang, Department of Gastroenterology, The First People's Hospital of Yunnan Province, 157 Jinbi Road, Xishan, Kunming, Yunnan 650032, P.R. China

E-mail: gqkj003@sina.com

E-mail: yuzhang320@sina.com

Key words: colorectal cancer, prune homolog 2 with $\mathrm{BCH}$ domain, proliferation, invasion, tumorigenicity

\section{Introduction}

Colorectal cancer (CRC) is one of the most common and deadliest cancers in the world, causing $~ 800,000$ deaths in 2018 (1). According to World Health Organization data, China had 245,000 new cases and 139,000 deaths associated with $\mathrm{CRC}$ in 2012, making it the fifth most common cancer in men and the fourth most common cancer in women (2). Among cases of CRC, $\sim 41 \%$ occur in the proximal colon, $\sim 22 \%$ in the distal colon and $28 \%$ involve the rectum (3). The occurrence and development of CRC is a complex pathological process involving multiple signaling pathways including Wnt, Hedgehog, bone morphogenic protein and Notch $(4,5)$. Therefore, identifying genes that serve an important role in CRC may help to identify therapeutic targets for CRC.

Human prune homolog 2 with $\mathrm{BCH}$ domain (PRUNE2) encodes a 340-kDa protein with a conserved $\mathrm{BCH}$ scaffold domain at its $\mathrm{C}$-terminus (6-8). Proteins with the $\mathrm{BCH}$ domain regulate morphogenesis, differentiation, motility and apoptosis by associating with components of signaling networks, such as Rho, Ras and MAPK signaling (7). Thus, PRUNE2 modulates cellular function, such as morphogenesis, differentiation, motility, proliferation and apoptosis, by modulating signaling networks. The function of PRUNE2 in numerous types of tumor has been reported, for example, increased expression of PRUNE2 is associated with favorable prognosis in neuroblastoma $(6,9)$; PRUNE2 also regulates the differentiation, proliferation and invasion of neuroblastoma tumor cells; moreover, increased PRUNE2 protein expression may serve as a favorable prognostic marker in human leiomyosarcoma $(10,11)$. PRUNE2 may serve antitumor functions, however, little is known about the effect of PRUNE2 on CRC.

The present study aimed to investigate the biological function of PRUNE2 in CRC cell lines (SW620 and HT29) by using Cell Counting Kit (CCK)-8, colony formation, flow cytometry and Transwell assay. Furthermore, a mouse model was established to investigate the effect of PRUNE2 on metastasis of CRC cells. 


\section{Materials and methods}

Gene expression and survival analysis. Gene expression RNA sequencing data from The Cancer Genome Atlas (TCGA) were obtained for colon adenocarcinoma (COAD) and rectal adenocarcinoma (READ) cohorts (12). mRNA expression levels were processed as previously described (13). The association between PRUNE2 expression and relapse-free survival probability was analyzed using the UALCAN website (ualcan. path.uab.edu/index.html). The expression levels of PRUNE2 in COAD, READ and matched adjacent normal tissue were analyzed using Gene Expression Profiling Interactive Analysis (gepia.cancer-pku.cn). The expression levels of PRUNE2 were analyzed in COAD cases with different stage and nodal metastasis status were analyzed via UALCAN.

Tissue collection. A total of $10 \mathrm{CRC}$ and adjacent healthy sections were collected between July and September 2020 from the Department of Pathology, First People's Hospital of Yunnan Province for western blot and immunohistochemistry assays. No patients received any adjuvant treatment, such as radiotherapy, chemotherapy or immunotherapy prior to surgery. Tissue histomorphology was confirmed by two pathologists in a blinded manner. The distance between CRC and adjacent tissue was $\geq 3 \mathrm{~cm}$. All patients (age, $62.6 \pm 11.82$ years; 5 male and 5 female) provided written informed consent. The present study was approved by the Ethics Committee of the First People's Hospital of Yunnan Province.

Immunohistochemistry. Tissues were fixed with $4 \%$ paraformaldehyde at room temperature overnight, then dehydrated, embedded in paraffin and sliced (thickness, $5 \mathrm{~mm}$ ). Sections were dewaxed with xylene and ethanol (xylene for 10 and $5 \mathrm{~min} ; 100 \%$ ethanol for $5 \mathrm{~min}$, then 95,80 and $70 \%$ ethanol for 2 min each). Sections were incubated with $3 \% \mathrm{H}_{2} \mathrm{O}_{2}$ for $10 \mathrm{~min}$ at room temperature to block endogenous peroxidase/phosphatase activity. Antigen repair was performed using $0.01 \mathrm{M}$ citric acid buffer ( $\mathrm{pH}$ 6.0) for $15 \mathrm{~min}$ at $100^{\circ} \mathrm{C}$ and $80 \mathrm{kPa}$. The sections were washed with $1 \mathrm{X}$ PBS three times for 5 min each and blocked with 5\% goat serum (Beijing Solarbio Science \& Technology Co., Ltd.) in PBS for $15 \mathrm{~min}$ at room temperature. Sections were incubated with PRUNE2 antibody (1:100; cat. no. 11458-1-AP; ProteinTech Group, Inc.) overnight at $4^{\circ} \mathrm{C}$. The sections were washed with $1 \mathrm{X}$ PBS three times for 5 min each and then incubated with horseradish peroxidase (HRP)-conjugated goat anti-rabbit IgG (1:200; cat. no. AS014; ABclonal Biotech Co., Ltd.) for $1.5 \mathrm{~h}$ at room temperature. The sections were washed with 1X PBS three times for $5 \mathrm{~min}$ each and visualized using a 3,3'-diaminobenzidine visualization kit (Fuzhou Maixin Biotech Co., Ltd.) according to the manufacturer's instructions. Sections were counterstained with $0.5 \%$ hematoxylin for 5-10 min at room temperature to visualize the nuclei. The sections were examined under a light microscope (x400 magnification). Brown staining indicated immunoreactive (positive) cells; blue staining indicated the nuclei. Positive expression of PRUNE2 was quantified using ImageJ 2x software (National Institutes of Health).

Cell culture. Human normal colorectal mucosa cells (FHC; CRL-1831) and CRC cell lines [SW620 (CCL-227), SW480
(CCL-228), HT29 (HTB-38), HCT116 (CCL-247), LOVO (CCL-229), DLD-1 (CCL-221)] were obtained from American Type Culture Collection. All cells were authenticated using STR profiling. The cells were maintained in high-glucose Dulbecco's modified Eagle's medium (DMEM) supplemented with $10 \%$ fetal bovine serum (FBS) and antibiotics (all Gibco; Thermo Fisher Scientific, Inc.) at $37^{\circ} \mathrm{C}$ in a humidified incubator containing $5 \% \mathrm{CO}_{2}$.

PRUNE2 overexpression and knockdown. For overexpression of PRUNE2, PRUNE2/pcDNA3.1 overexpression plasmid was purchased from Shanghai GeneChem Co., Ltd. For knockdown of PRUNE2, negative control (NC) short hairpin (sh)RNA oligo (UUCUCCGAACGUGUCACGUTT) and PRUNE2 shRNA (GGGCCAGAATATCGATGAATT) were purchased from Shanghai GeneChem Co., Ltd. For cell transfection, SW620 and HT29 cells $\left(1 \times 10^{5}\right)$ were plated in a 6 -well plate at $37^{\circ} \mathrm{C}$ overnight. Then, 100 pmol PRUNE2 or NC shRNA or $2 \mu \mathrm{g}$ PRUNE2/pcDNA3.1 or empty pcDNA3.1 vector and $15 \mathrm{ml}$ Lipofectamine ${ }^{\circledR} 2000$ (cat. no. 11668-019; Invitrogen; Thermo Fisher Scientific, Inc.) were incubated at room temperature for $20 \mathrm{~min}$ according to the manufacturer's instructions. Mixtures were transfected into cells for $48 \mathrm{~h}$ at $37^{\circ} \mathrm{C}$, then the subsequent experimentation was performed. For cell experiments, SW620 and HT29 cells were divided into five groups as follows: Normal (untransfected cells); control (ctrl; transfected with empty pcDNA3.1 vector); PRUNE2 (transfected with PRUNE2/pcDNA3.1 vector); shRNA-NC (transfected with NC shRNA) and shRNA-PRUNE2 (transfected with PRUNE2 shRNA).

Reverse transcription-quantitative (RT-q)PCR. Total RNA was extracted from cells using TRIzol ${ }^{\circledR}$ (cat. no. 1596-026; Invitrogen; Thermo Fisher Scientific, Inc.). cDNA was reverse-transcribed using the RevertAid ${ }^{\mathrm{TM}}$ First Strand cDNA Synthesis kit (cat. no. K1622; Fermentas; Thermo Fisher Scientific, Inc.) according to the manufacturer's protocol, and subjected to amplification using THERMO Maxima ${ }^{\circledR}$ SYBR Green/ROX qPCR Master Mix (cat. no. K0223; Thermo Fisher Scientific, Inc.) as follows: $95^{\circ} \mathrm{C}$ for $3 \mathrm{~min}$; followed by 40 cycles of $95^{\circ} \mathrm{C}$ for $10 \mathrm{sec}$ and $60^{\circ} \mathrm{C}$ for $60 \mathrm{sec}$. The relative expression levels of PRUNE2 were measured by RT-qPCR using an ABI PRISM 7500 system (Thermo Fisher Scientific, Inc.). All samples were normalized to $\beta$-actin and all experiments were performed in triplicate. The mean value was used to calculate relative mRNA expression levels using the $2^{-\Delta \Delta \mathrm{Cq}}$ method (14). Primers (Sangon Biotech Co., Ltd.) were as follows: PRUNE2 forward, 5'-GGGTCTTCTGGGATTATG G-3' and reverse, 5'-CTGGGCTAACAAGGTCTAC-3' and $\beta$-actin forward, 5'-CATCGTCCACCGCAAATGCTTC-3' and reverse, 5'-ACCGACTGCTGTCACCTTCAC-3'.

Western blot assay. Total protein from cells and tissues was obtained using RIPA lysis buffer (cat. no. R0020; Beijing Solarbio Science \& Technology Co., Ltd.), and then quantified by BCA protein Assay. For each sample, $40 \mu \mathrm{g} /$ lane protein was loaded onto $10 \%$ SDS-PAGE gel, separated for $120 \mathrm{~min}$ at $120 \mathrm{~V}$ and transferred to a PVDF membrane. Following blocking with $10 \%$ skimmed milk for $2 \mathrm{~h}$ at room temperature, the membranes were incubated overnight at $4^{\circ} \mathrm{C}$ with 
antibodies against PRUNE2 (1:1,000; cat. no. 11458-1-AP; ProteinTech Group, Inc.), Bcl-2 (1:1,000; cat. no. 26593-1-AP; ProteinTech Group, Inc.), Bax (1:1,000; cat. no. 60267-1-Ig; ProteinTech Group, Inc.), caspase-3 (1:1,000; cat. no. 19677-1-AP; ProteinTech Group, Inc.), caspase-9 (1:1,000; cat. no. 10380-1-AP; ProteinTech Group, Inc.), Cyclin D1 (1:1,000; cat. no. 60186-1-Ig; ProteinTech Group, Inc.) or $\beta$-actin (1:2,000; cat. no. ab8227; Abcam). Following washing with $1 \mathrm{X}$ TBST (cat. no. T1085; Beijing Solarbio Science \& Technology Co., Ltd.) three times for $10 \mathrm{~min}$ each, membranes were incubated with HRP-conjugated goat anti-rabbit or anti-mouse (both 1:2,000; cat. nos. A0208 and A0216, respectively; both Beyotime Institute of Biotechnology) for $1.5 \mathrm{~h}$ at room temperature. The blots were washed with $1 \mathrm{X}$ TBST three times for 10 min each and developed with Immobilon Western Chemiluminescent HRP Substrate (cat. no. WBKLS0100; MilliporeSigma). The bands were imaged with a chemiluminescence imager (Bio-Rad Laboratories, Inc.). The band intensities were determined using ImageJ $2 x$ software (National Institutes of Health) and normalized to $\beta$-actin.

Cell proliferation assay. Cell proliferation was detected by CCK-8) assay. A total of $2 \times 10^{4}$ cells/well was seeded into 96-well plates. After incubation at $37^{\circ} \mathrm{C}$ for $24 \mathrm{~h}$, cells were transfected with PRUNE2/pcDNA3.1 or PRUNE2 shRNA for 48 h. Then, $10 \mu$ l CCK-8 solution (cat. no. CP002; Signalway Antibody, LLC) was added to each well and cells were incubated at $37^{\circ} \mathrm{C}$ for $2 \mathrm{~h}$. The absorbance was measured at $450 \mathrm{~nm}$ using a microplate reader (cat. no. DNM-9602; Perlong Medical Equipment Co., Ltd.).

Cell cycle assay. Following transfection for 48 h, both SW620 and HT29 cells were trypsinized, collected and centrifuged at $1,000 \mathrm{x} \mathrm{g}$ for $3 \mathrm{~min}$ at $4^{\circ} \mathrm{C}$. Cells were washed with $1 \mathrm{X}$ PBS and fixed in $70 \%$ ethanol for $24 \mathrm{~h}$ at $4^{\circ} \mathrm{C}$. Cells were incubated in $100 \mathrm{ml}$ RNase A solution (1 mg/ml; cat. no. R8020-25; Beijing Solarbio Science \& Technology Co., Ltd.) in the dark at $37^{\circ} \mathrm{C}$ for $30 \mathrm{~min}$ and stained with $400 \mathrm{ml}$ propidium iodide (PI) solution (50 $\mu \mathrm{g} / \mathrm{ml}$; cat. no. C001-200; Shanghai Qihai Futai Biological Technology Co., Ltd.) in the dark at room temperature for $10 \mathrm{~min}$. Following staining, cells were analyzed with a flow cytometer (Accuri C6; BD Biosciences). BD Accuri C6 plus software (3.1.1.0; BD Biosciences) was used for analysis. Red fluorescence was detected at excitation wavelength of $488 \mathrm{~nm}$, corresponding to BD Biosciences flow cytometry FL2 detection channel.

Colony formation assay. Both SW620 and HT29 cells were trypsinized and resuspended in DMEM. A total of $10 \mathrm{ml}$ medium containing 700 cells was added to each well of a $10 \mathrm{~mm}$ culture dish. After incubation at $37^{\circ} \mathrm{C}$ for $24 \mathrm{~h}$, the cells were transfected with PRUNE2/pcDNA3.1 or PRUNE2 shRNA for $48 \mathrm{~h}$ and cultured at $37^{\circ} \mathrm{C}$ in an incubator for 7 days; medium was replaced with fresh medium every 3 days. After 7 days, the cells were washed with $1 \mathrm{X}$ PBS three times. Then, $5 \mathrm{ml}$ $4 \%$ paraformaldehyde was used to fix cells for $15 \mathrm{~min}$ at room temperature and $5 \mathrm{ml} 0.5 \%$ crystal violet staining solution (cat. no. C8470; Beijing Solarbio Science \& Technology Co., Ltd.) was added for $20 \mathrm{~min}$ at room temperature to stain the cells. The cells were washed with $1 \mathrm{X}$ PBS and air dried and colonies (>50 cells) visible to the naked eye were counted manually.
Cell invasion assay. Cell invasion assay was performed using 8- $\mu \mathrm{m}$ Transwell chambers (cat. no. 3422; Corning, Inc.) precoated with Matrigel (cat. no. 356234; Corning, Inc.) for $30 \mathrm{~min}$ at $37^{\circ} \mathrm{C}$. Following transfection for $24 \mathrm{~h}, 200 \mu \mathrm{l}$ cell suspension within DMEM $\left(4 \times 10^{5}\right.$ cells $\left./ \mathrm{ml}\right)$ was added to the upper chamber and $700 \mu \mathrm{l}$ DMEM containing 10\% FBS was added to the lower chamber. Following incubation at $37^{\circ} \mathrm{C}$ for $48 \mathrm{~h}$, the cells were fixed with $4 \%$ formaldehyde for $10 \mathrm{~min}$ at room temperature and invading cells were stained with $0.5 \%$ crystal violet (cat. no. C8470; Beijing Solarbio Science \& Technology Co., Ltd.) for $30 \mathrm{~min}$ at room temperature and air dried. The invading cells on the lower membrane surface were imaged under a light microscope and counted.

Apoptosis assay. Following transfection for $48 \mathrm{~h}, 1 \times 10^{5}$ cells (SW620 and HT29) were collected and centrifuged at 1,000 $\mathrm{x} g$ for 5 min at $4^{\circ} \mathrm{C}$. Cells were resuspended in $195 \mu \mathrm{l}$ Annexin V-APC binding buffer (cat. no. E-CK-A151; Elabscience Biotechnology, Inc.) and stained with $5 \mu \mathrm{l}$ Annexin V-APC staining solution (cat. no. E-CK-A117; Elabscience Biotechnology, Inc.) in the dark at $4^{\circ} \mathrm{C}$ for $15 \mathrm{~min}$. The cells were stained with $5 \mu$ PI staining solution (cat. no. E-CK-A161; Elabscience Biotechnology, Inc.) in the dark at $4^{\circ} \mathrm{C}$ for 5 min. Finally, $400 \mu \mathrm{l}$ binding buffer was added and samples were assessed using flow cytometer (Accuri C6; BD Biosciences). BD Accuri C6 plus software (3.1.1.0; BD Biosciences) was used for analysis. Tubes without Annexin V-APC or PI were used as NC. APC (blue) was detected at an excitation wavelength of $652 \mathrm{~nm}$. PI (red) was detected at an excitation wavelength of $488 \mathrm{~nm}$. The percentage of apoptotic cells was calculated as early + late apoptotic cells.

Tumor xenografts in mice. A total of 12 female BALB/c nude mice (weight, $18 \pm 2 \mathrm{~g}$; age, 6-8 weeks; Charles River Laboratories, Inc.) were house with free food and water under specific-pathogen-free conditions at $21-25^{\circ} \mathrm{C}$ with $40-70 \%$ humidity and 12/12-h light/dark cycle. The animal experimental procedures were in accordance with Yunnan Administration Guidelines for Laboratory Animals and approved by the Animal Ethics Committee of Kunming University of Science and Technology. pGV492-gcGFP and pGV492-gcGFP-PRUNE2 overexpression vector (Shanghai GeneChem Co., Ltd.) were transfected into SW620 cells as aforementioned. Following $48 \mathrm{~h}$ transfection, cells were trypsinized with $0.25 \%$ trypsin (Gibco) and sub-cultured. Following cell adherence, puromycin (cat. no. P8230; Beijing Solarbio Science \& Technology Co., Ltd.) was added at $5 \mu \mathrm{g} / \mathrm{ml}$ for screening cells and solution was replaced with complete DMED with $5 \mu \mathrm{g} / \mathrm{ml}$ puromycin every 2-3 days. After 1 week, cells were cultured in complete medium with $2 \mu \mathrm{g} / \mathrm{ml}$ puromycin. RT-qPCR was performed to verify the expression levels of PRUNE2 in the screened PRUNE2-GFP-SW620 and the NC-GFP-SW620 cells. Cell lines successfully screened were named NC-GFP-SW620 and PRUNE2-GFP-SW620. A total of $2 \times 10^{6}$ NC-GFP- or PRUNE2-GFP-SW620 cells in $0.1 \mathrm{ml}$ PBS were subcutaneously injected into the axilla of mice. A total of 12 mice were randomly divided into two groups ( $\mathrm{n}=6 /$ group) as follows: NC-GFP-SW620 and PRUNE2-GFP-SW620. All mice were anesthetized with pentobarbital sodium $(50 \mathrm{mg} / \mathrm{kg})$ by intraperitoneal injection at 5, 10, 15, 20 and 25 days after inoculation, then fluorescence of cell inoculation sites in mice was 
A

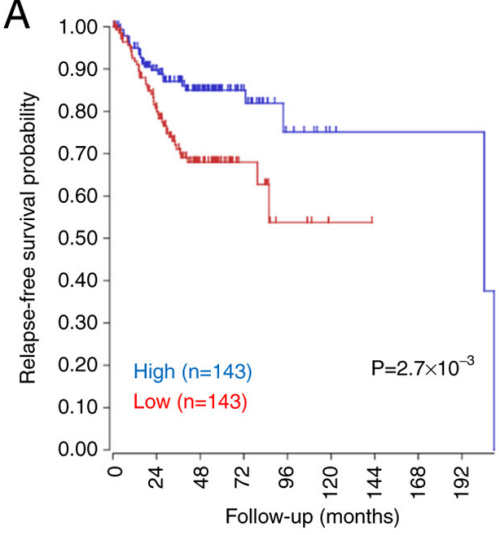

D

Expression of PRUNE2 in COAD based on nodal metastasis status

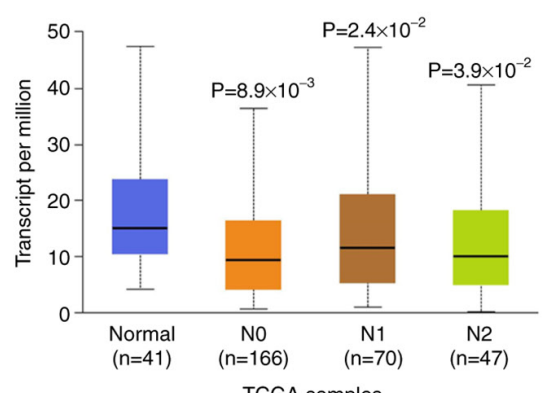

TCGA samples

$\mathrm{F}$

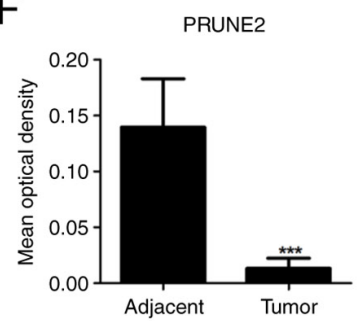

B

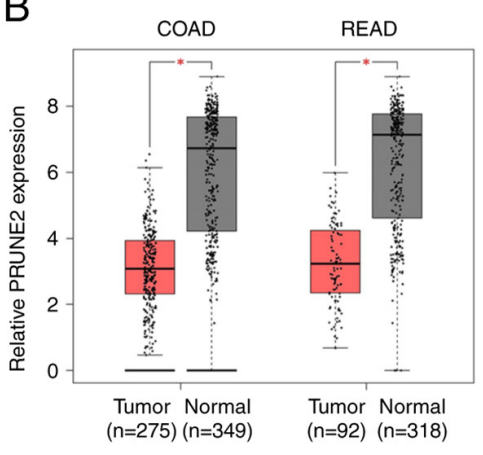

$E$

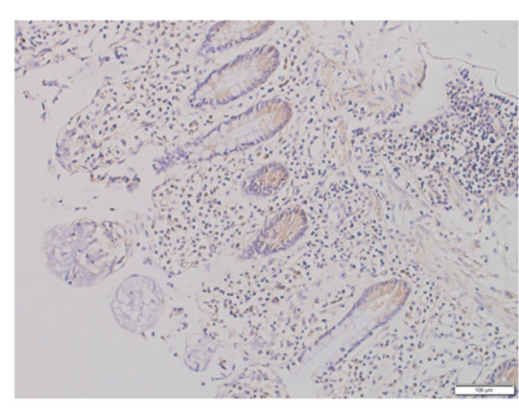

C

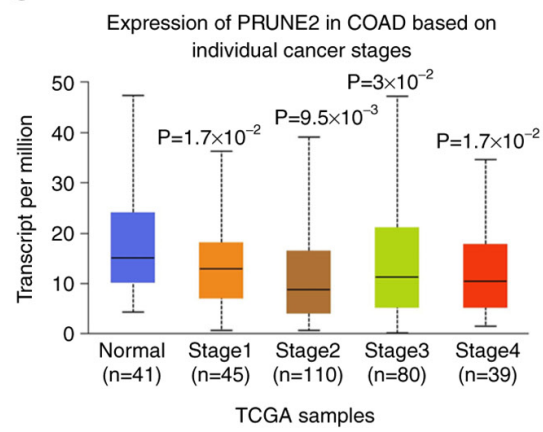

Tumor

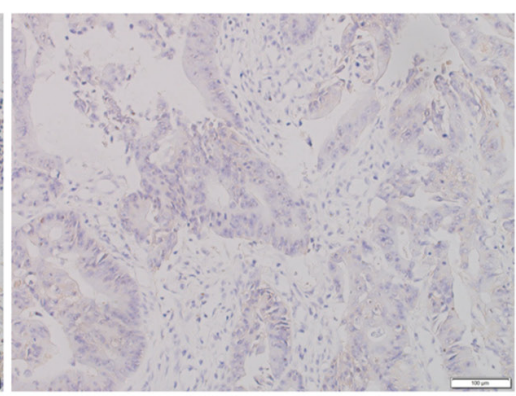

$\mathrm{H}$

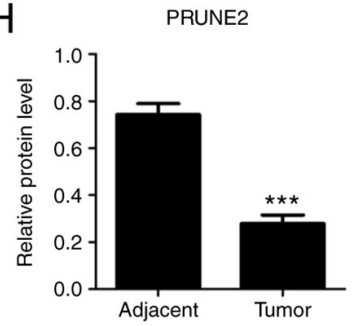

Figure 1. PRUNE2 downregulation in human CRC predicts poor recurrence-free survival. (A) Kaplan-Meier survival curves of relapse-free survival probability of patients with CRC with high and low levels of PRUNE2. The log-rank test was used for statistical analysis. (B) Expression levels of PRUNE2 were analyzed in COAD, READ and matched adjacent normal tissue. The expression levels of PRUNE2 were analyzed in COAD based on (C) cancer stage and (D) nodal metastasis status. These data were extracted from the TCGA. (E) PRUNE2 protein expression in CRC and adjacent tissue was using immunohistochemistry (magnification, x200). Scale bar, $100 \mathrm{~mm}$. (F) Quantification of PRUNE2 expression using ImageJ software. (G) PRUNE2 protein expression in CRC and adjacent tissue was detected using western blot assay and $(\mathrm{H})$ quantified. Data are presented as the mean \pm SD (n=5). Data were analyzed using Student's t-test. ${ }^{*} \mathrm{P}<0.05,{ }^{* * *} \mathrm{P}<0.001$ vs. adjacent (normal). PRUNE2, prune homolog 2 with BCH domain; CRC, colorectal cancer; COAD, colon adenocarcinoma; READ, rectal adenocarcinoma; TCGA, The Cancer Genome Atlas.

observed using an IVIS ${ }^{\circledR}$ Spectrum In Vivo Bioluminescence imaging system (PerkinElmer, Inc.) at 5, 10, 15, 20 and 25 days after inoculation. Tumor diameter was measured with Vernier calipers every 3 days after tumor emergence (14 days after inoculation) to measure tumor volume $[$ (volume $=(4 / 3) \times \pi \times$ radius $^{3}$ ] for 18 days before mice were sacrificed. All mice were euthanized with pentobarbital sodium $(150 \mathrm{mg} / \mathrm{kg})$ by intraperitoneal injection and cervical dislocation. Subcutaneous tumors were collected at 32 days after cell injection.

Statistical analysis. Data are presented as the mean \pm SD. All experiments were performed in triplicate. All data were analyzed using GraphPad Prism 5.0 software (GraphPad Software, Inc.). The log-rank test statistical analysis was used for the curves of relapse-free survival probability. Differences between two groups were analyzed using paired Student's t-test. Differences between $>2$ groups were compared using one-way
ANOVA followed by Tukey's-post hoc test. $\mathrm{P}<0.05$ was considered to indicate a statistically significant difference.

\section{Results}

PRUNE2 downregulation is associated with poor CRC patient survival. A total of 286 patients were included for relapse-free survival probability analysis using clinical and PRUNE2 expression data from TCGA. There was a significant difference in relapse-free survival probability between patients with low and high PRUNE2 levels, suggesting that low PRUNE2 expression was associated with lower relapse-free survival probability (Fig. 1A). Statistical analysis of mRNA expression data from TCGA showed that PRUNE2 was underexpressed in COAD and READ compared with adjacent normal tissue (Fig. 1B). Moreover, expression of PRUNE2 was significantly downregulated in CRC tissue compared with adjacent normal 
A

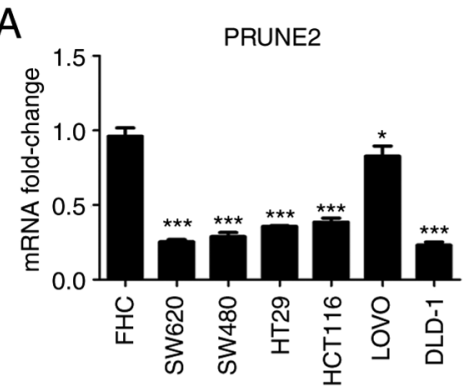

B

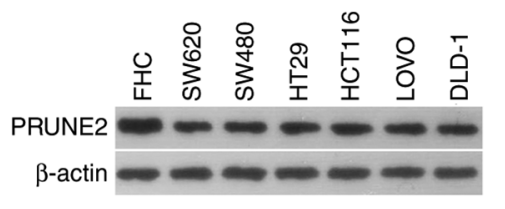

PRUNE2

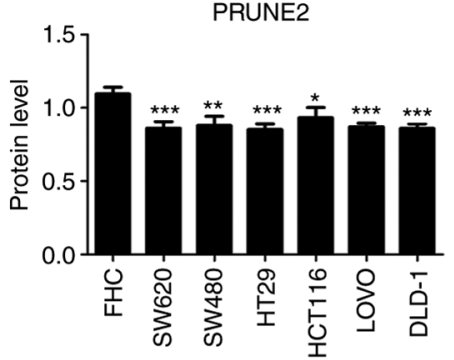

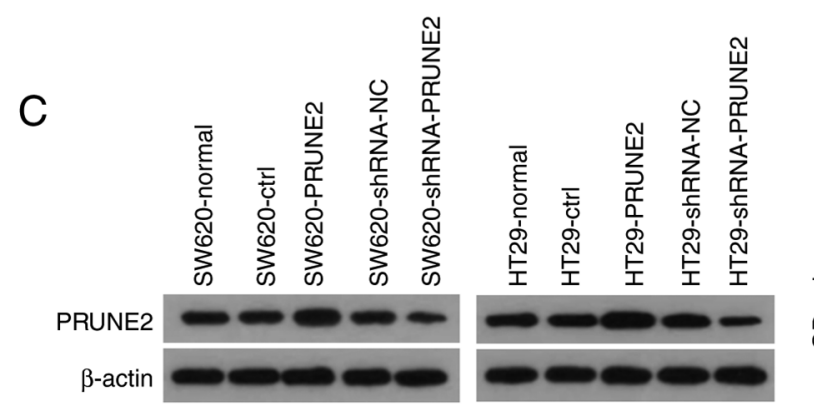

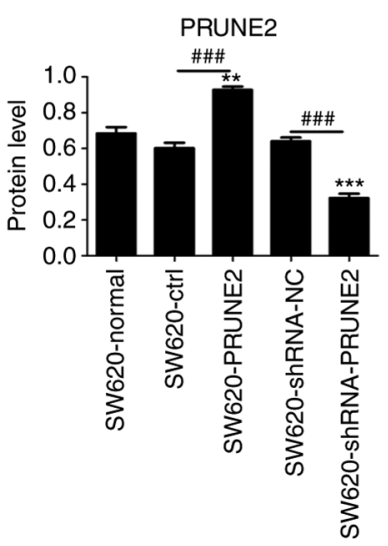

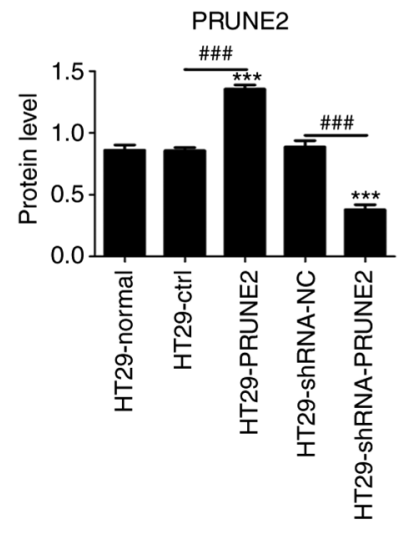
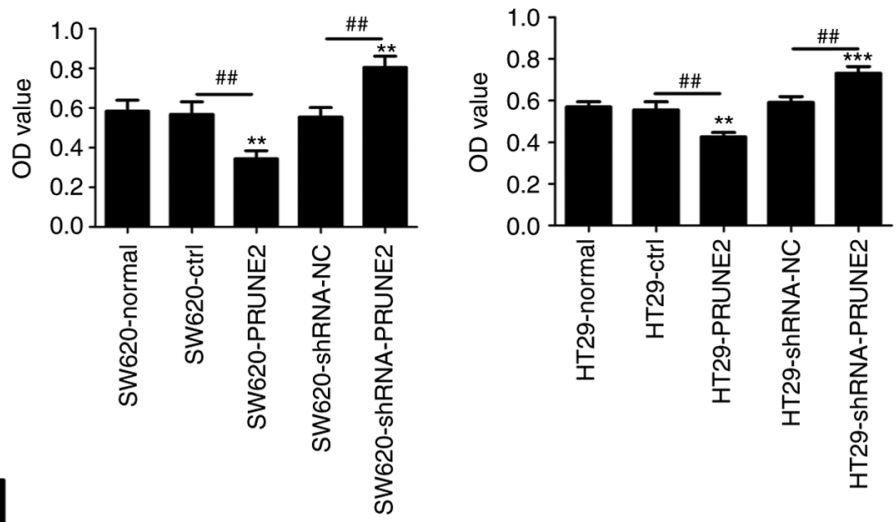

Figure 2. PRUNE2 expression levels in cell lines and effect on cell viability. (A) mRNA and (B) protein levels in human normal colorectal mucosa cells (FHC) and CRC cell lines (SW620, SW480, HT29, HCT116, LOVO, DLD-1) were determined by reverse transcription-quantitative PCR and western blotting, respectively. ${ }^{*} \mathrm{P}<0.05,{ }^{* *} \mathrm{P}<0.01,{ }^{* * *} \mathrm{P}<0.001$ vs. FHC. (C) Transfection efficiency of the pCDNA3.1/PRUNE2 plasmid and shRNA PRUNE2 were detected by western blot assay. (D) Viability of CRC cells was detected by Cell Counting Kit- 8 assay. Data are presented as the mean \pm SD ( $n=3$ ). Data were analyzed using one-way ANOVA. ${ }^{* *} \mathrm{P}<0.01,{ }^{* * *} \mathrm{P}<0.001$ vs. normal; ${ }^{\# \#} \mathrm{P}<0.01,{ }^{\# \# /} \mathrm{P}<0.001$. PRUNE2, prune homolog 2 with $\mathrm{BCH}$ domain; sh, short hairpin; CRC, colorectal cancer; OD, optical density; ctrl, control; NC, negative control.

tissue at all tumor stages (Fig. 1C) and metastasis statuses (Fig. 1D). Immunohistochemistry of paired CRC and normal tissue revealed that PRUNE2 was primarily localized in the cytoplasm and its expression levels were lower in CRC compared with adjacent tissue (Fig. 1E and F). The western blotting results were consistent with the immunohistochemistry results, the expression levels of PRUNE2 was lower in tumor tissues compared with adjacent tissue (Fig. 1G and $\mathrm{H}$ ). These data indicated that PRUNE2 was downregulated in $\mathrm{CRC}$ and associated with poor patient survival.

Effect of PRUNE2 on viability of CRC cell lines. PRUNE2 expression was detected in human normal colorectal mucosa cells (FHC) and six CRC cell lines (SW620, SW480, HT29, HCT116, LOVO, DLD-1) using RT-qPCR and western blotting. PRUNE2 mRNA levels were lower in CRC cell lines compared with FHC cells (Fig. 2A). Western blotting results were consistent with RT-qPCR results, PRUNE2 protein levels were lower in CRC cell lines compared with FHC cells (Fig. 2B). Two CRC cell lines (SW620 and HT29) were randomly selected from several cells with low expression and used in subsequent experiments. PRUNE2 was overexpressed or knocked down via transient transfection of the pcDNA3.1/PRUNE2 vector and shRNA PRUNE2 into the SW620 and HT29 CRC cell lines; empty pcDNA3.1 vector and shRNA NC were used as controls. Western blotting was performed to evaluate protein levels of PRUNE2; PRUNE2 was significantly upregulated by pcDNA3.1/PRUNE2 and downregulated by PRUNE2 shRNA in SW620 and HT29 cells (Fig. 2C). CCK-8 assay revealed that PRUNE2 overexpression significantly decreased proliferation and PRUNE2 knockdown significantly increased proliferation of CRC cells (Fig. 2D). These data indicated that PRUNE2 was expressed at low levels and decreased viability in CRC cell lines.

Effect of PRUNE2 on colony formation and invasion of CRC cell lines. To determine the effect of PRUNE2 on colony 
A
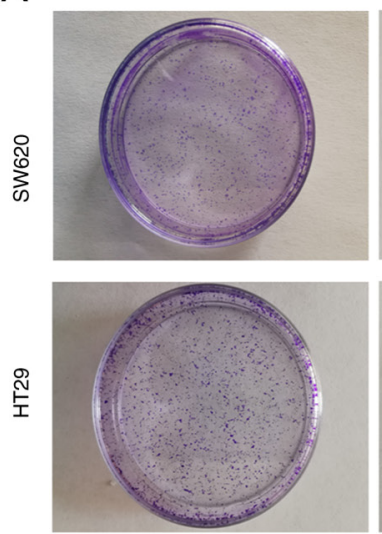

B
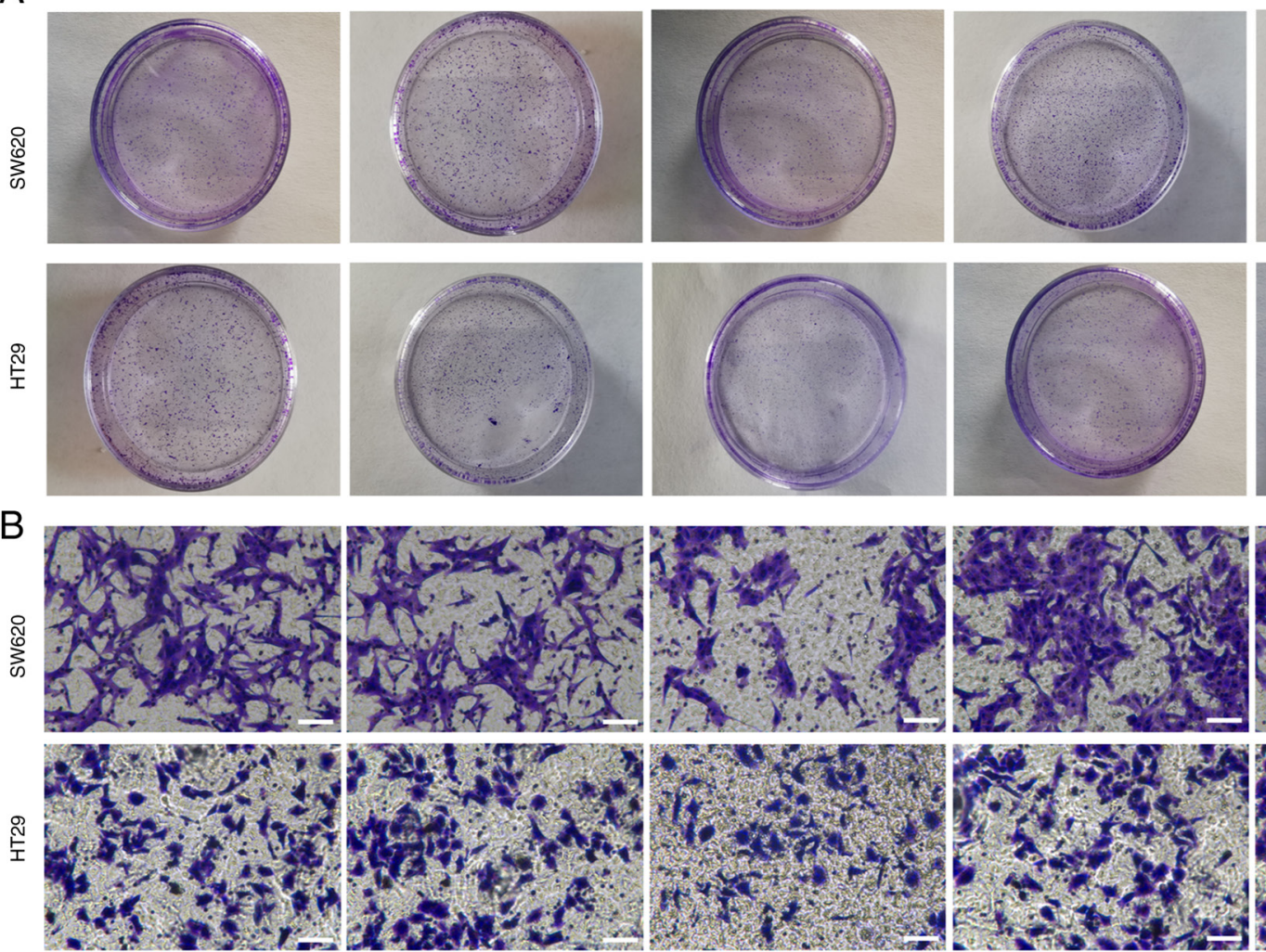

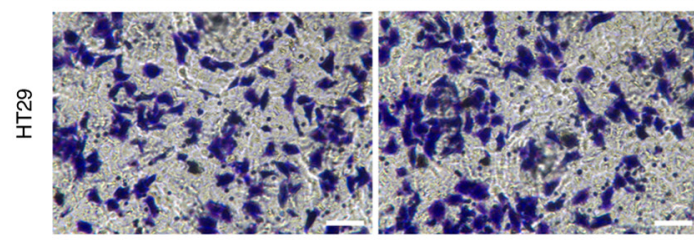

C

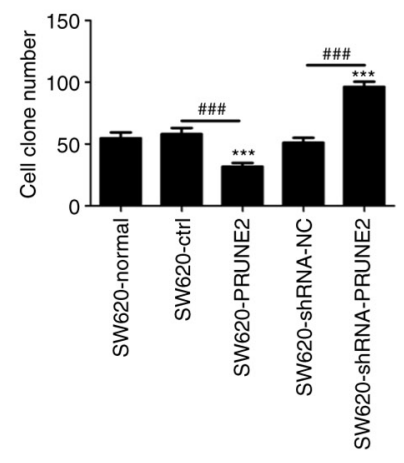

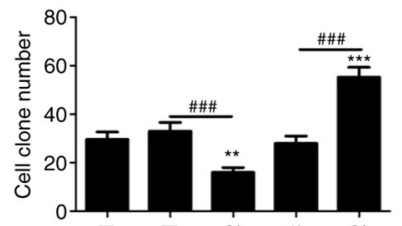

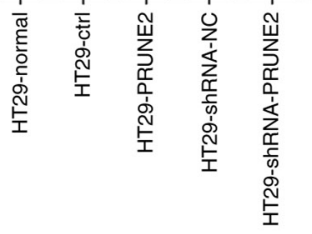

D

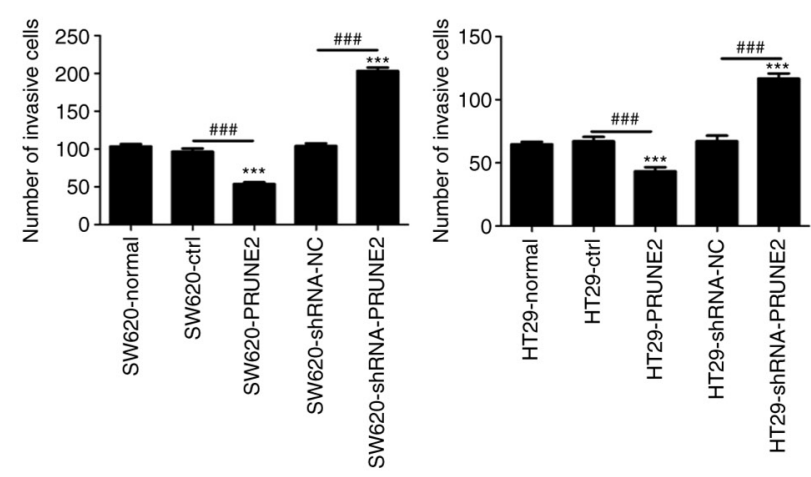

Figure 3. Effect of PRUNE2 on colony formation and invasion in CRC cells. (A) Colony formation of CRC cells was assessed by staining with crystal violet. (B) Cell invasion was detected using Transwell assay. Representative images are shown. Magnification, x200. Scale bar, $100 \mu \mathrm{m}$. (C) Number of stained colonies in CRC cells. (D) Number of invaded cells was counted. Data are presented as the mean $\pm \mathrm{SD}(\mathrm{n}=3)$. Data were analyzed using one-way ANOVA. ${ }^{* *} \mathrm{P}<0.01$, ${ }^{* * * *} \mathrm{P}<0.001$ vs. normal; ${ }^{\# \# \#} \mathrm{P}<0.001$. PRUNE2, prune homolog 2 with BCH domain; CRC, colorectal cancer; ctrl, control; sh, short hairpin; NC, negative control.

formation and invasion, colony formation and Transwell assays were performed on two CRC cell lines. PRUNE2 overexpression significantly decreased the number of cell colonies, whereas PRUNE2 knockdown significantly increased the number of cell colonies (Fig. 3A and C), suggesting that PRUNE2 may be involved in regulating clonogenic ability of CRC cells. Transwell assay demonstrated that the number of invading cells in the PRUNE2 group was significantly decreased and that in the shRNA-PRUNE2 group was significantly increased compared with the ctrl and shRNA-NC groups, respectively (Fig. 3B and D). These results indicated that PRUNE2 inhibited proliferation and invasion of CRC cell lines.

PRUNE2 overexpression arrests CRC cells at $G_{0} / G_{1}$ stage and induces apoptosis. The effect of PRUNE2 on CRC cell cycle progression was detected by flow cytometry. The results indicated increased accumulation of CRC cells in $G_{0} / G_{1}$ phase in the PRUNE2 group compared with the ctrl (Fig. 4A and B). This was accompanied by a significant decrease in the percentage of cells in $S$ phase. PRUNE2 knockdown decreased the percentage of cells in $G_{0} / G_{1}$ phase, and increased the percentage of cells in $S$ phase. To determine the effect of PRUNE2 on cell apoptosis, annexin/PI double staining kit and flow cytometry were used. The results indicated that apoptosis was significantly decreased in CRC cells transfected with PRUNE2 shRNA and significantly increased in CRC cells transfected with PRUNE2 overexpressing cells compared with NC and ctrl, respectively (Fig. 4C and D). These data indicated that PRUNE2 overexpression prevented $G_{0} / G_{1}$ to $S$ stage transition and promoted cell apoptosis. 
A
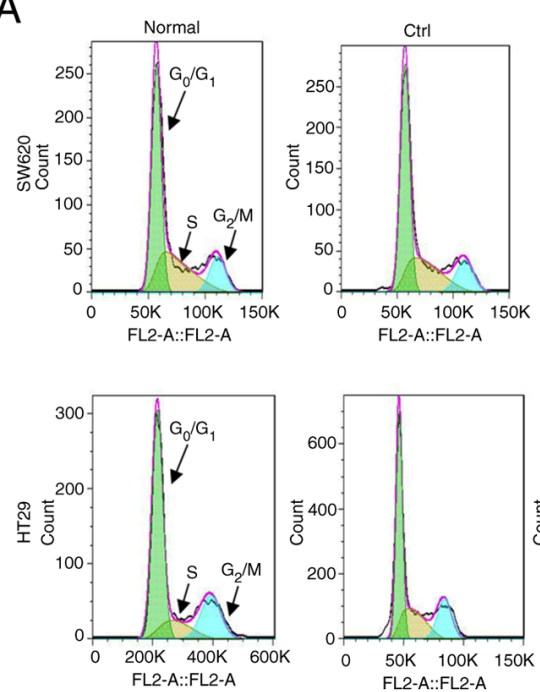

C
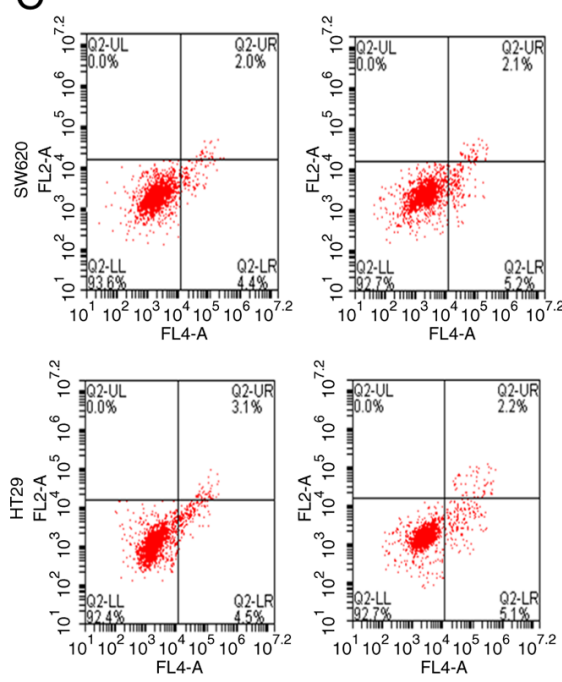
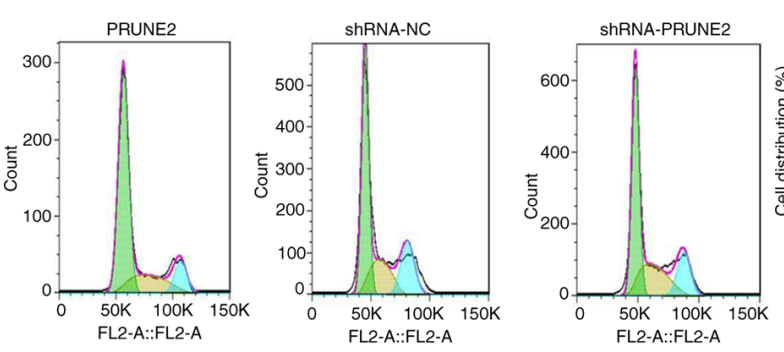

B
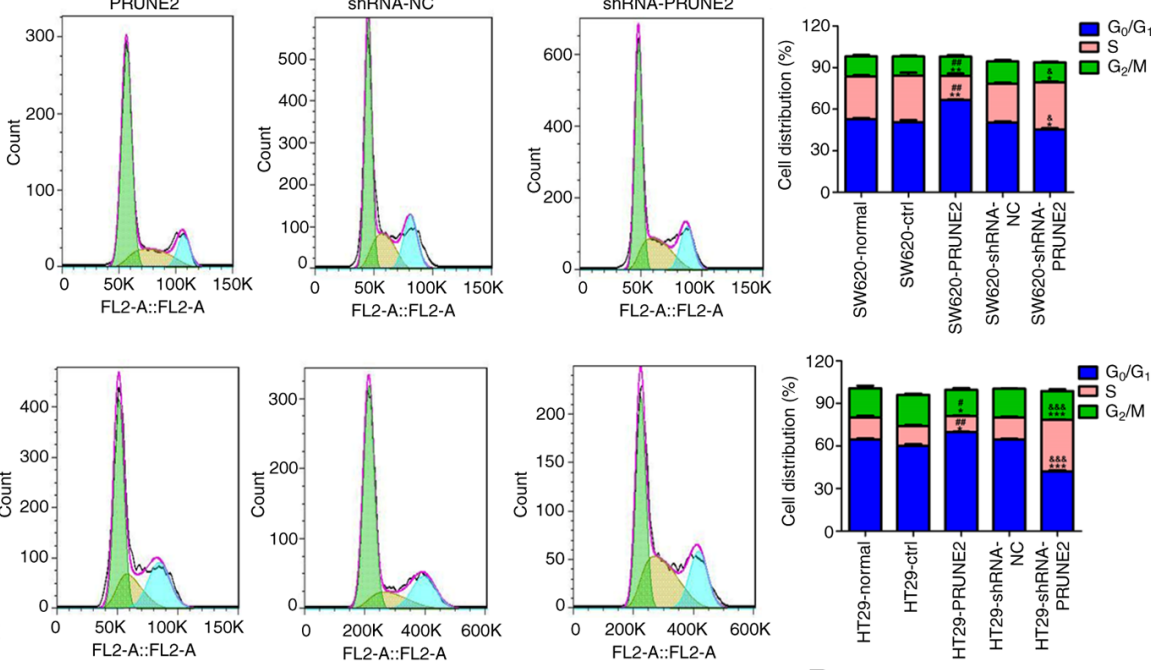

D
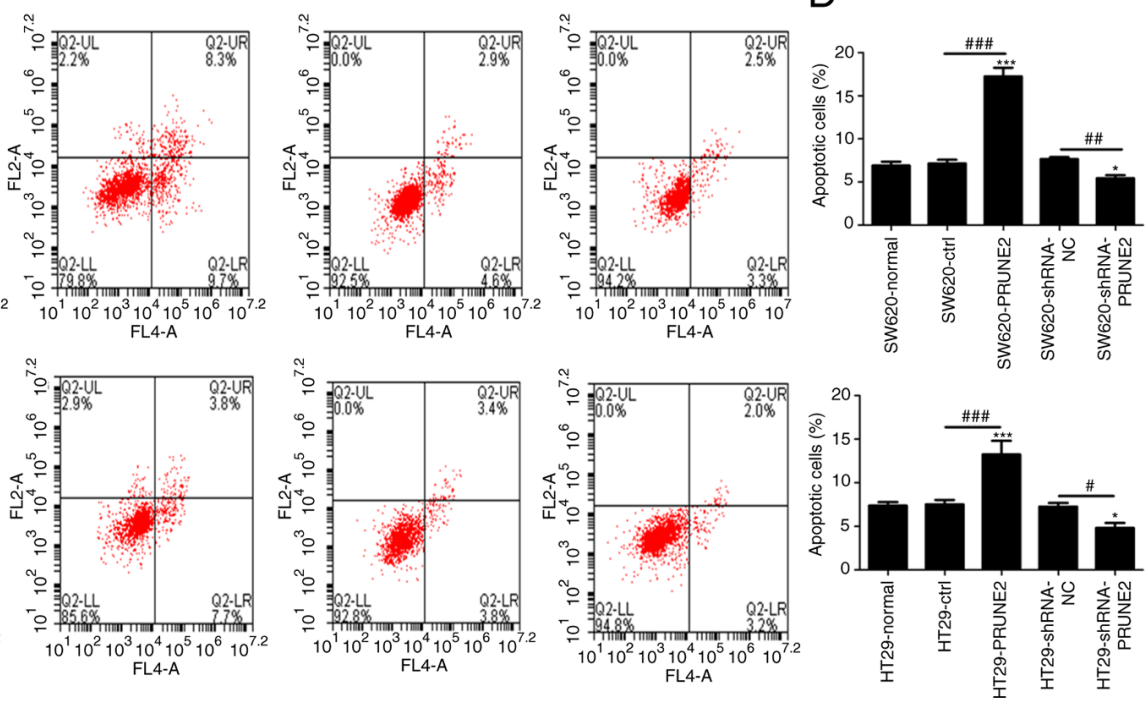

Figure 4. Effect of PRUNE2 on CRC cell cycle progression and apoptosis. (A) Flow cytometric analysis of cell cycle progression. (B) Quantitative results of cell cycle distribution. (C) Apoptosis (right quadrants) in CRC cells was detected by flow cytometry with an Annexin V-APC/PI double staining kit. The X-axis represents APC-stained cells; y-axis represents PI-stained cells. (D) Ratio of apoptotic cells among CRC cells. Data are presented as the mean \pm SD ( $=3$ ). Data were analyzed using one-way ANOVA. ${ }^{*} \mathrm{P}<0.05,{ }^{* *} \mathrm{P}<0.01$ and ${ }^{* * * *} \mathrm{P}<0.001$ vs. normal; ${ }^{*} \mathrm{P}<0.05,{ }^{\# \#} \mathrm{P}<0.01$ and ${ }^{\# \# \#} \mathrm{P}<0.001$ vs. ctrl; ${ }^{\&} \mathrm{P}<0.05$ and ${ }^{\& \& \&} \mathrm{P}<0.001$ vs. shRNA-NC. PRUNE2, prune homolog 2 with BCH domain; CRC, colorectal cancer; ctrl, control; sh, short hairpin; NC, negative control.

PRUNE2 expressionin CRC cells decreases protein expression of apoptosis markers. As aforementioned, PRUNE2 induced cell apoptosis. Hence, western blotting was used to detect protein levels of Bcl-2, Bax, caspase-3, caspase-9 and Cyclin D1. PRUNE2 overexpression significantly increased expression of proapoptotic proteins Bax, caspase- 3 and caspase-9 and significantly decreased expression of antiapoptotic proteins Bcl-2 and Cyclin D1 in CRC cell lines (Fig. 5A and B). These results indicated PRUNE2 overexpression promoted the expression of apoptotic markers.

Tumor growth is inhibited by PRUNE2 overexpression in vivo. To investigate the putative role of PRUNE2 in CRC cells in vivo, tumorigenic potential of PRUNE2-GFP-SW620 cells was assessed in a mouse tumor xenograft model. Expression levels of PRUNE2 in screened PRUNE2-GFP-SW620 and NC-GFP-SW620 cells were detected by RT-qPCR, showed significant high expression in the PRUNE2-GFP-SW620 group compared with that of the NC-GFP-SW620 group (Fig. 6A). The size, weight and growth curves of xenograft tumors were significantly decreased in the PRUNE2 overexpression compared with the NC-GFP group (Fig. 6B-D). Fluorescence in vivo bioluminescence imaging demonstrated that PRUNE2 overexpression markedly inhibited tumorigenic ability of CRC cells and tumor growth in mice at 5, 10, 15, 20 and 25 days after inoculation (Fig. 6E). These results indicated that PRUNE2 overexpression suppressed the proliferation of CRC cells in vivo and confirmed results obtained in vitro.

\section{Discussion}

Due to its high incidence, late diagnosis and poorly understood molecular mechanisms, there is a lack of effective treatments for CRC, especially for patients with advanced disease (15). There is therefore a need to characterize the disease and identify novel promising treatments. PRUNE2, a human 


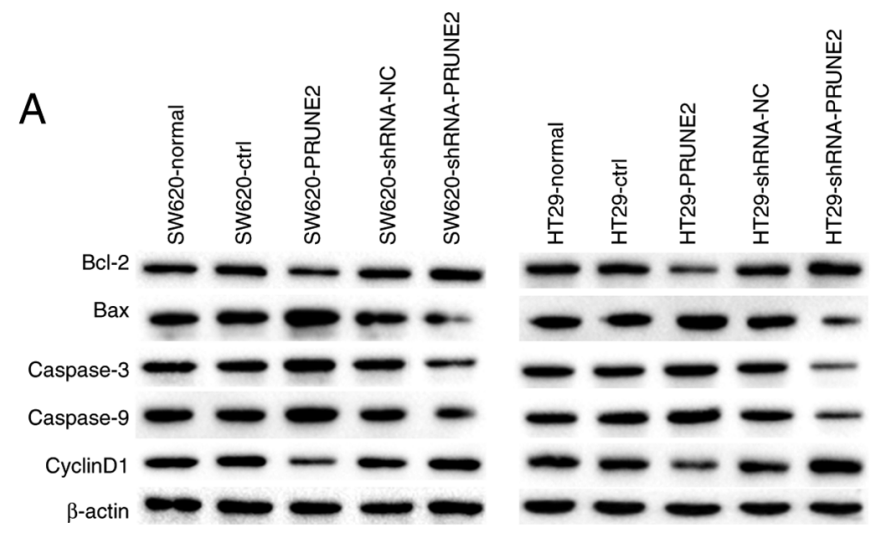

B
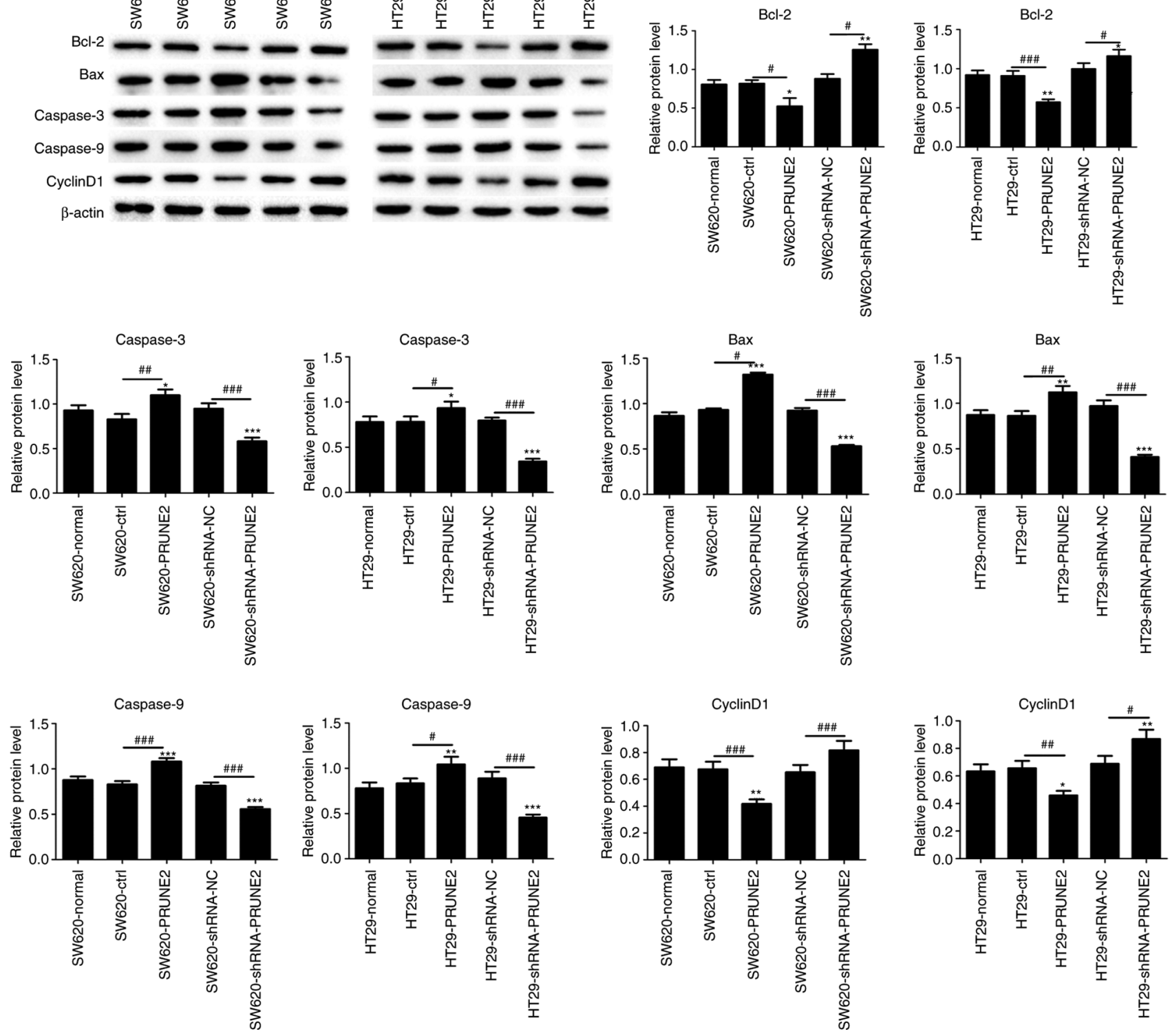

Figure 5. Effect of PRUNE2 on expression of apoptotic markers in colorectal cells. (A) Western blot analysis of expression levels of apoptotic (Bax, caspase-3 and caspase-9) and antiapoptotic proteins (Bcl-2 and Cyclin D1) with $\beta$-actin as a loading control. (B) Quantitative results of Bcl-2, Bax, caspase-3, caspase-9 and cyclin D1 protein levels relative to $\beta$-actin. Data are presented as the mean $\pm \mathrm{SD}(\mathrm{n}=3)$. Data were analyzed using one-way ANOVA. ${ }^{*} \mathrm{P}<0.05$, ${ }^{* * *} \mathrm{P}<0.01$ and ${ }^{* * * *} \mathrm{P}<0.001$ vs. normal; ${ }^{~} \mathrm{P}<0.05,{ }^{\# \#} \mathrm{P}<0.01$ and ${ }^{\# \# \#} \mathrm{P}<0.001$. PRUNE2, prune homolog 2 with $\mathrm{BCH}$ domain; ctrl, control; sh, short hairpin; NC, negative control.

homolog of the Drosophila prune gene, is regulated by long non-coding RNAs in human prostate cancer and serves as a tumor suppressor (16). PRUNE2 homolog 2 is a susceptibility gene for Alzheimer's disease and an important regulator of Rho signaling $(9,17)$. PRUNE2 is constitutively expressed in adult nerve (18) and prostate tissue (19), which indicates that, in addition to promoting apoptosis in neuroblastoma, PRUNE2 may serve a physiological role in these tissues. PRUNE2 is downregulated in epithelial-derived skin, prostate and colon cancer tissue (8), which suggests that inhibition of PRUNE2 expression may be associated with tumor progression. However, the function of PRUNE2 in CRC is still unknown. To the best of our knowledge, the present study is the first to demonstrate that PRUNE2 serves a key role in CRC cells both in vivo and in vitro.

Using clinical data from TCGA, PRUNE2 was shown to be downregulated in colorectal tumor samples compared with normal colorectal tissue. Although most prior studies have reported that PRUNE2 expression is decreased in various types of cancer $(6,10,11,16)$, including prostate cancer, neuroblastoma and leiomyosarcoma, few studies have investigated PRUNE2 expression in CRC. Low PRUNE2 expression is associated with poor long-term clinical outcomes in patients with CRC (20). Meta-analysis of patients treated with bevacizumab identified PRUNE2 as a prognostic biomarker for CRC (20). This supports the hypothesis that PRUNE2 serves 
A

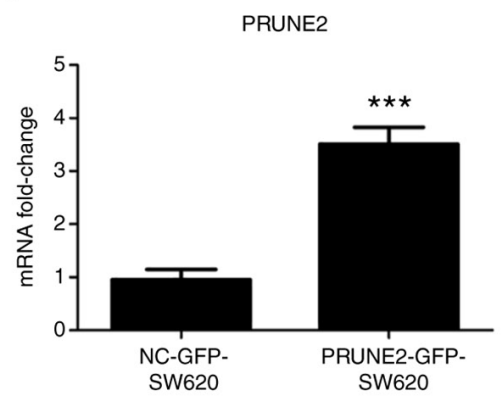

C

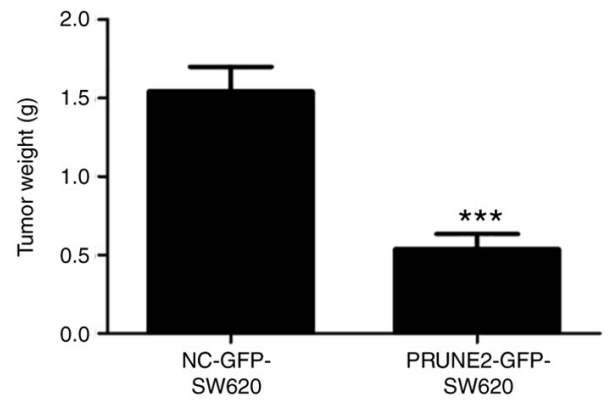

B

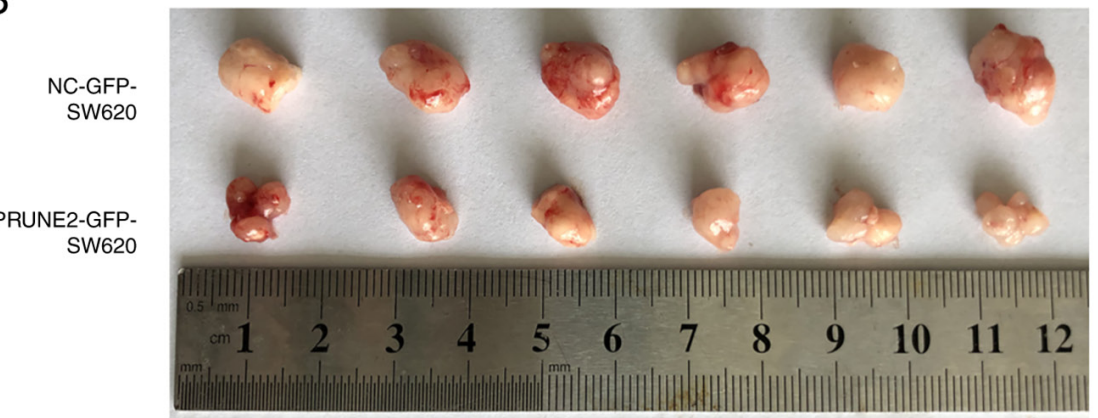

E 5 10 15 20

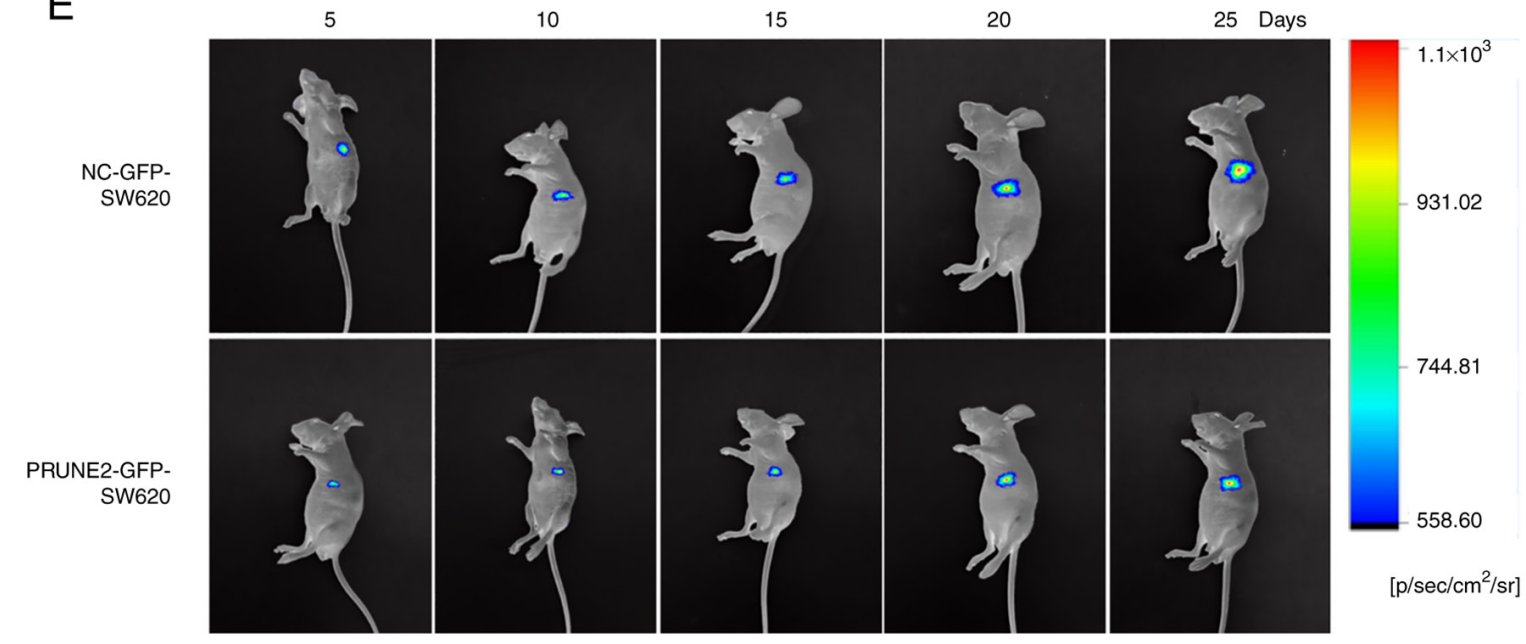

Figure 6. PRUNE2 overexpression inhibits tumorigenic ability of SW620 cells in vivo. (A) Expression levels of PRUNE2 in NC-GFP-SW620 and PRUNE2-GFP-SW620 cells were measured by reverse transcription-quantitative PCR. (B) Representative images of mouse xenograft tumors derived from NC-GFP-SW620 and PRUNE2-GFP-SW620 groups. Subcutaneous tumors were collected 32 days after inoculation. (C) Tumor weight was measured. Data were analyzed using Student's t-test. (D) Growth curves (volume) of xenograft tumors in NC-GFP-SW620 and PRUNE2-GFP-SW620 groups at 0, 3, 6, 9, 12, 15 and 18 days after emergence of the subcutaneous tumors. Data were analyzed using two-way ANOVA. (E) Fluorescence of cell inoculation sites in mice were observed using an In Vivo Bioluminescence imaging system at 5, 10, 15, 20 and 25 days after inoculation. Data are presented as the mean \pm SD ( $=6$ ). ${ }^{* * *} \mathrm{P}<0.001$ vs. NC-GFP-SW620. PRUNE2, prune homolog 2 with BCH domain; NC, negative control; p, pico; sr, steradian.

as tumor suppressor gene of CRC. The present immunohistochemistry and western blot assays also exhibited low expression of PRUNE2 in CRC tissue. These results suggested that PRUNE2 may be a human CRC suppressor. Numerous studies have revealed that PRUNE2 expression is associated with various types of cancer $(6,10,11,16)$. PRUNE2 may contribute to the maintenance of mature nervous systems (18). In addition, PRUNE2 mRNA expression is associated with the survival of patients with leiomyosarcoma (21). DNA damage induces programmed expression of PRUNE2 during apoptosis in neuroblastoma cells (22). PRUNE2 also serves a role in suppressing prostate cancer (16). To the best of our knowledge, however, few studies have reported PRUNE2 expression in
CRC. The functional role of PRUNE2 in the proliferation, invasion and apoptosis of CRC cells remains to be reported.

PRUNE2 was previously reported to have low expression in colon cancer (8), but its function in CRC has not previously been reported. Here, PRUNE2 overexpression suppressed the proliferation, invasion and colony formation of CRC cells and induced cell cycle arrest in $\mathrm{G}_{0} / \mathrm{G}_{1}$ stage, which suggested that PRUNE2 may be associated with proliferative capacity of CRC cells; by contrast, PRUNE2 silencing increased cell proliferation and invasion. PRUNE2 regulates cell cycle transition in neuroblastoma cells (23). The present study observed arrest in $G_{0} / G_{1}$ phase following overexpression of PRUNE2; these results indicated a 
potential role of PRUNE2 in DNA replication. The present study demonstrated that upregulation of PRUNE2 decreased cell proliferation. Salameh et al (16) reported that PRUNE2 overexpression decreases proliferation of prostate cancer cells. Flow cytometric analysis revealed that PRUNE2 overexpression promoted apoptosis of CRC cells, suggesting that PRUNE2 may inhibit CRC development via apoptosis inhibition. This supports the hypothesis that PRUNE2 promotes cell death triggered by apoptotic stimuli (8). In neuroblastoma and prostate cancer, PRUNE2 protein is highly expressed and serves a prognostic role $(6,24)$. However, the association between PRUNE2 expression and its prognostic role in CRC requires further study. Increased methylation of PRUNE2 promoter is associated with nodal metastasis and inversely associated with PRUNE2 expression in head and neck cancer (25). Further studies are required to identify potential genes that regulate expression of PRUNE2 by regulating the promoter or methylation of PRUNE2 and thus influence the development of CRC. PRUNE2 regulates cell processes (26) and signaling (7), such as Rho, Ras and MAPK signaling; it may have a similar regulation mode to other tumors or exhibit a CRC-specific regulation pattern; further studies should investigate this.

PRUNE2 inhibits expression of Bcl-2 and other antiapoptotic Bcl-2 family proteins to promote mitochondrial apoptosis in DNA-damaged cells and caspase- 3 and caspase-9 activation are mediated by PRUNE2 expression (8). The present study detected expression of apoptosis-associated proteins Bcl-2, Bax, caspase-3, caspase-9 and Cyclin D1 using western blot assay. PRUNE2 overexpression increased expression of proapoptotic proteins and decreased expression of antiapoptotic proteins in CRC cell lines. Cyclin D1 is a $\mathrm{G}_{1}$ phase cyclin and protooncogene that binds to and activates cyclin-dependent kinases in $G_{1}$ phase to facilitate entry into $S$ phase and promote cell cycle progression $(27,28)$.

To confirm the effect of PRUNE2 on CRC, a nude mouse tumor xenograft model was generated. PRUNE2 overexpression markedly inhibited the weight and growth of xenograft tumors. These results indicated that PRUNE2 overexpression suppressed the tumorigenic ability of CRC cells in vivo and confirmed results obtained in vitro. Limitations exist in the present study; the mechanism by which PRUNE2 promotes apoptosis in CRC is unknown and the association between PRUNE2 expression and CRC development was not analyzed. Investigation of the association between PRUNE2 level and CRC grade and degree of malignancy is required to understand the potential biomarker role of PRUNE2 in CRC. Future studies should investigate the mechanism by which PRUNE2 promotes apoptosis in CRC.

The functional role of PRUNE2 in proliferation, invasion and apoptosis of CRC cells remains to be reported. To the best of our knowledge, the present study is the first to report that expression levels of PRUNE2 are associated with development of CRC by promoting proliferation and invasion and inhibiting apoptosis. CRC cells with higher expression of PRUNE2 showed decreased proliferation and invasion and lower tumorigenic ability, suggesting that PRUNE2 may be involved in CRC development and may be a potential tumor suppressor in CRC. Further investigation of the association between PRUNE2 and CRC is required to understand the role of PRUNE2 in CRC. The present study suggested that PRUNE2 may function as a tumor-suppressive gene in CRC.

\section{Acknowledgements}

Not applicable.

\section{Funding}

The present study was supported by the National Natural Science Foundation of China (grant no. 81860522), Yunnan Health Training Project of High Level Talents (grant no. H-2018039), Joint Foundation of Kunming Medical University and Yunnan Provincial Science and Technology Department (grant nos. 202001AY070001-114 and 2019FE001-121), Internal Division of Yunnan Provincial Health Commission (grant no. 2018NS0263) and Clinical Medical Center of Yunnan Provincial Health Commission (grant no.2020LCZXKF-XH03).

\section{Availability of data and materials}

The datasets used and/or analyzed during the current study are available from the corresponding author on reasonable request.

\section{Authors' contributions}

YZ and QG conceived and supervised the study. TL, YZ and QG designed the study. TL, SH and WY performed the experiments and analyzed the data. TL, YZ and QG confirm the authenticity of all the raw data. All authors have read and approved the final manuscript.

\section{Ethics approval and consent to participate}

The present study was approved by the Ethics Committee of The Affiliated Hospital of Kunming University of Science and Technology (approval no. KHLL2021-YJ097) and the Animal Ethics Committee of Kunming University of Science and Technology (approval no. 202060446). Written informed consent was obtained from all participants.

\section{Patient consent for publication}

Not applicable.

\section{Competing interests}

The authors declare that they have no competing interests.

\section{References}

1. Bray F, Ferlay J, Soerjomataram I, Siegel RL, Torre LA and Jemal A: Global cancer statistics 2018: GLOBOCAN estimates of incidence and mortality worldwide for 36 cancers in 185 countries. CA Cancer J Clin 68: 394-424, 2018.

2. Gu MJ, Huang QC, Bao CZ, Li YJ, Li XQ, Ye D, Ye ZH, Chen K and Wang JB: Attributable causes of colorectal cancer in China. BMC Cancer 18: 38, 2018.

3. Cheng L, Eng C, Nieman LZ, Kapadia AS and Du XL: Trends in colorectal cancer incidence by anatomic site and disease stage in the United States from 1976 to 2005. Am J Clin Oncol 34: 573-580, 2011. 
4. Vinson KE, George DC, Fender AW, Bertrand FE and Sigounas G: The notch pathway in colorectal cancer. Int J Cancer 138: 1835-1842, 2016.

5. Geissler K and Zach O: Pathways involved in Drosophila and human cancer development: The notch, hedgehog, wingless, runt, and trithorax pathway. Ann Hematol 91: 645-669, 2012.

6. Machida T, Fujita T, Ooo ML, Ohira M, Isogai E, Mihara M, Hirato J, Tomotsune D, Hirata T, Fujimori M, et al: Increased expression of proapoptotic BMCC1, a novel gene with the BNIP2 and $\mathrm{Cdc} 42 \mathrm{GAP}$ homology $(\mathrm{BCH})$ domain, is associated with favorable prognosis in human neuroblastomas. Oncogene 25: 1931-1942, 2006.

7. Pan CQ and Low BC: Functional plasticity of the BNIP-2 and Cdc42GAP Homology $(\mathrm{BCH})$ domain in cell signaling and cell dynamics. FEBS Lett 586: 2674-2691, 2012.

8. Tatsumi Y, Takano R, Islam MS, Yokochi T, Itami M, Nakamura Y and Nakagawara A: BMCC1, which is an interacting partner of BCL2, attenuates AKT activity, accompanied by apoptosis. Cell Death Dis 6: e1607, 2015.

9. Soh UJ and Low BC: BNIP2 extra long inhibits RhoA and cellular transformation by Lbc RhoGEF via its $\mathrm{BCH}$ domain. J Cell Sci 121: 1739-1749, 2008.

10. Zhao LR, Tian W, Wang GW, Chen KX and Yang JL: The prognostic role of PRUNE2 in leiomyosarcoma. Chin J Cancer 32 648-652, 2013

11. Price ND, Trent J, El-Naggar AK, Cogdell D, Taylor E, Hunt KK Pollock RE, Hood L, Shmulevich I and Zhang W: Highly accurate two-gene classifier for differentiating gastrointestinal stromal tumors and leiomyosarcomas. Proc Natl Acad Sci USA 104: 3414-3419, 2007.

12. Cancer Genome Atlas Network: Comprehensive molecular characterization of human colon and rectal cancer. Nature 487: 330-337, 2012.

13. Vaidyanathan S, Cato K, Tang L,Pavey S, Haass NK, Gabrielli BG and Duijf PH: In vivo overexpression of Emil promotes chromosome instability and tumorigenesis. Oncogene 35: 5446-5455, 2016.

14. Livak KJ and Schmittgen TD: Analysis of relative gene expression data using real-time quantitative PCR and the 2(-Delta Delta C(T)) method. Methods 25: 402-408, 2001

15. Kazemi T, Younesi V, Jadidi-Niaragh $\mathrm{F}$ and Yousefi $\mathrm{M}$ Immunotherapeutic approaches for cancer therapy: An updated review. Artif Cells Nanomed Biotechnol 44: 769-779, 2016.

16. Salameh A, Lee A, Cardó-Vila M, Nunes DN, Efstathiou E, Staquicini FI, Dobroff AS, Marchiò S, Navone NM, Hosoya $\mathrm{H}$, et al: PRUNE2 is a human prostate cancer suppressor regulated by the intronic long noncoding RNA PCA3. Proc Natl Acad Sci USA 112: 8403-8408, 2015.

17. Potkin SG, Guffanti G, Lakatos A, Turner JA, Kruggel F, Fallon JH, Saykin AJ, Orro A, Lupoli S, Salvi E, et al: Hippocampal atrophy as a quantitative trait in a genome-wide association study identifying novel susceptibility genes for Alzheimer's disease. PLoS One 4: e6501, 2009.
18. Iwama E, Tsuchimoto D, Iyama T, Sakumi K, Nakagawara A Takayama K, Nakanishi Y and Nakabeppu Y: Cancer-related PRUNE2 protein is associated with nucleotides and is highly expressed in mature nerve tissues. J Mol Neurosci 44: 103-114, 2011.

19. Harris JL, Richards RS, Chow CW, Lee S, Kim M, Buck M, Teng L, Clarke R, Gardiner RA and Lavin MF: BMCC1 is an AP-2 associated endosomal protein in prostate cancer cells. PLoS One 8: e73880, 2013.

20. Quintanilha JCF, Wang J, Sibley AB, Xu W, Espin-Garcia O, Jiang C, Etheridge AS, Ratain MJ, Lenz HJ, Bertagnolli M, et al: Genome-wide association studies of survival in 1520 cancer patients treated with bevacizumab-containing regimens. Int J Cancer 150: 279-289, 2022.

21. Yang JL, Cogdell D, Eddy J, Trent J, Price N and Zhang W: Expression of PRUNE2 mRNA and its positive correlation with non-coding RNA PCA3 in leiomyosarcoma. Zhonghua Zhong Liu Za Zhi 34: 497-500, 2012 (In Chinese).

22. Islam MR, Takano R, Yokochi T, Akter J, Nakamura Y, Nakagawara A and Tatsumi Y: Programmed expression of pro-apoptotic BMCC1 during apoptosis, triggered by DNA damage in neuroblastoma cells. BMC Cancer 19: 542, 2019.

23. Islam MS, Tatsumi Y, Takano R, Yokochi T, Akter J, Ozaki T, Nakamura Y, Ohira M and Nakagawara A: Transcriptional regulation of $\mathrm{BMCC} 1$ mediated by $\mathrm{E} 2 \mathrm{~F} 1$ in neuroblastoma cells. Biochem Biophys Res Commun 478: 81-86, 2016.

24. Clarke RA, Zhao Z, Guo AY, Roper K, Teng L, Fang ZM, Samaratunga H, Lavin MF and Gardiner RA: New genomic structure for prostate cancer specific gene PCA3 within BMCC1: Implications for prostate cancer detection and progression. PLoS One 4: e4995, 2009.

25. Su SC, Yeh CM, Lin CW, Hsieh YH, Chuang CY, Tang CH, Lee YC and Yang SF: A novel melatonin-regulated lncRNA suppresses TPA-induced oral cancer cell motility through replenishing PRUNE2 expression. J Pineal Res 71: e12760, 2021.

26. Bozgeyik E, Kocahan S, Temiz E and Bagis H: miR-19a and miR-421 target PCA3 long non-coding RNA and restore PRUNE2 tumor suppressor activity in prostate cancer. Mol Biol Rep: Nov 27, 2021 (Epub ahead of print). doi: 10.1007/s11033021-06996-5.

27. Masuda M, Hirakawa N, Nakashima T, Kuratomi Y and Komiyama S: Cyclin D1 overexpression in primary hypopharyngeal carcinomas. Cancer 78: 390-395, 1996.

28. Bayat Z, Ghaemi Z, Behmanesh M and Soltani BM: Hsa-miR-186-5p regulates TGF $\beta$ signaling pathway through expression suppression of SMAD6 and SMAD7 genes in colorectal cancer. Biol Chem 402: 469-480, 2021.

This work is licensed under a Creative Commons Attribution-NonCommercial-NoDerivatives 4.0 International (CC BY-NC-ND 4.0) License. 